\title{
The diffusion of world sports events between 1891 and 2010: A study on globalisation
}

\section{Julie Borgers ${ }^{1}$, Bart Vanreusel ${ }^{1}$ and Jeroen Scheerder ${ }^{1}$}

\author{
${ }^{1}$ Katholieke Universiteit Leuven, Belgium
}

\begin{abstract}
This study addresses the geographical diffusion of modern world sports events (WSEs) from the perspective of globalisation. Based on objective criteria, 27 WSEs organised by international sporting bodies (ISBs) are selected. Between 1891 and 2010, these ISBs organised a total number of 850 WSEs. The first part of the analysis observes the global diffusion of WSE editions over six distinct macro-geographical regions. In the second part of our study, a more detailed view is obtained by bringing the global diffusion of host cities into focus.

Patterns of diffusion of WSEs have been developing towards a global phenomenon since the second half of the $20^{\text {th }}$ century. WSEs have contributed to the global development of other fields such as talent migration, global sports media coverage and finance flows, and can therefore be considered as agents of globalisation. Moreover, WSEs can be seen as the result of local interests and the decision-making of international power networks in sport. It is argued that the observed diffusion of WSEs, as an exponent of globalising physical culture, is a subject of increasing global governance.
\end{abstract}

Keywords: globalisation, diffusion, world sports events, host locations, governance

\section{Introduction}

Modern sport, being a prominent expression of human physical culture, is featured by a process of globalisation (Bale \& Maguire, 1994; Guttman, 1994; Maguire, 1999; 2011). Globalisation has been interpreted by Giddens (1990) as a network of intensifying and interconnecting worldwide social relations, in which local events are related to and shaped by major agents all around the world. As outlined by Appadurai (1990), the global flow of mediascapes, technoscapes, financescapes, ethnoscapes and ideoscapes is a central motor for processes of globalisation. These dynamic spheres also affect the two most prominent sports modes, that is, professional sports on the one hand, and mass sports, including the physical fitness industry, on the other (Bale \& Maguire, 1994). In this paper we will focus on the global diffusion of world sports events (WSEs) as a predominant form of actual physical culture.

In his analysis of sport as a function system, Stichweh (2012) notices that modern sport increasingly presents itself as an event-based culture, with constant production and a global consumption of sports events. When considering the global and local impact of sports spectacles such as the Olympic Games, it is common to refer to them as mega sports events or MSEs (Brownell \& Parry, 2012; Gratton \& Taylor, 
2000; Hiller, 2012; Short, 2004; 2008). In general, requirements to be considered an MSE are threefold and releate to local impact, international significance and global media coverage (Roche, 2000; Horne \& Manzenreiter, 2006). For the purpose of the current study, however, smaller sports spectacles will also be taken into account. Hence, world sports events (WSEs) can be defined as professional or professionalising elite sports competitions accessible for athletes from all over the world. These are the most important and world encompassing championships in a sports discipline, organised by international sporting bodies (ISBs). WSEs can represent either uni sports events or multi sports events and are increasingly represented as major commodified spectacles for global audiences and markets.

The growth of international sports events can be understood as the result of an increasing organisational capacity and the internationalisation of sports organisations. However, we consider this perspective as being too narrow to understand adequately the global diffusion process of WSEs. That is, it overlooks the emergence of complex global and local power networks that surround the competitive arena of sports events; bid campaigns, formal and informal decision-making, organisations, the intersection of local and global interests (such as economic development, tourism, community building and general sports development), and common or contradictory interests of nation states, cities, local and supranational markets and social organisations. From this point of view, global sports development has become a key business concern for governments and sports organisations (Girginov \& Sandanski, 2008).

Although the complex process of hosting a WSE demands significant resources (Hiller, 2012), and economic impact studies have shown that it generally does not generate the benefits that are often claimed (Kavetsos \& Szymanski, 2010; Késenne, 2005), the number of candidate nations and cities seeking to host a WSE has substantially grown over the years (Cornelissen, 2004; Preuss, 2006; Short, 2008). The bidding process itself can be understood as a continuous strategic and tactical process of interaction between local and global forces. Despite the often overestimated economic impact, the popularity of the bidding process can therefore be approached from different perspectives (Gugler, 2004; Hiller, 2012; Horne, 2007; Horne \& Manzenreiter, 2006). A prime reason to endorse entering the bidding for WSEs can be related to political globalisation and the rise of a sense of nationalism as a reaction to this (Roche, 2006; Short, 2004, 2008; Tomlinson \& Young, 2006). Secondly, cities seek opportunities for their development by hosting a WSE. That is, hosting a major event is considered a significant tool for economic development of cities for example through television revenues, facilities, tourism, city marketing and urban development (Gold \& Gold, 2008; Horne \& Manzenreiter, 2006; Preuss, 2006). Furthermore, several authors also claim that by hosting a WSE, local community development can be endorsed via reinforced social capital and social networks. Opportunities for local participation may be fostered by direct or indirect involvement by citizens through 
volunteering, and building awareness and interest in sport (Hiller, 2012; Misener \& Mason, 2006; Preuss \& Solberg, 2006). Moreover, it is claimed that WSEs are able to generate socio-psychological benefits by means of feelings of well-being, pride, joy or unity on local and national levels (Howard \& Crompton, 2004; Schokkaert, Swinnen \& Vondemoortele, 2012). More specifically, Carey, Mason and Misener (2011) have argued that intangible motives such as legacy, social transformation or catalyst opportunities for cities are particularly present in bidding documents and proposals of so-called non-traditional nations or cities with emergent economies. In sum, although evidence for most of these claims is scarce or even non-existent, the common belief in the benefits of hosting sport spectacles may be a major catalyst in the global diffusion of WSEs.

The global diffusion of WSEs is also influenced by the growing power and expansion of international sports bodies and their associations with governmental organisations and multinational corporations. Requirements and rules established by those powerful bodies often influence final decisions (Hargreaves, 2002), which may directly impact on the popularity and global diffusion of a sport (van Bottenburg, 2001). Hence, the globalisation of sport is not just a uniform and homogeneous process of expansion. Rather it can be understood as the result of strong interaction between interdependent economic, political, social and cultural factors. This implies that it is an uneven process which exhibits great variation (Hargreaves, 2002). The control of human performance, produced as commodified spectacles for global audiences, has become an object of local and global strive.

Although a spectrum of concepts and theories of globalisation is available to help understand the increasing tendency of sport operating on a worldwide scale (Guttmann, 1994; Hargreaves, 2002; Held, McGrew, Coldplatt \& Perraton, 1999; Maguire, 1999; Miller, Lawrence, McKay \& Rowe, 2001), no unified coherent theory on sports globalisation has generally been accepted (Hargreaves, 2002). This paper, however, is inspired by the theoretical framework on globalisation put forward by Martinelli (2003). He suggests that, "the study of world society and its relations with national and local social realities should become a central theme of research" (Martinelli, 2003, 292). In his attempt to address the challenges of globalisation, Martinelli explains the concept of global governance. In his view, the diffusion of WSEs is the result of "global institutional actors having different and often conflicting interests and identities. But they all serve to connect and integrate, and in doing so foster complex patterns of world governance" (Martinelli, 2003, 315). In this analysis of the global diffusion of elite sports events we share Martinelli's perspective: "The higher the degree of interconnectedness of social relations at the world level, the greater the need to analyse the links between global social reality and multiple local social realities. ... At the cultural level we must analyse the many ways in which the unity and the diversity of the world combine and collide; at the social level we should 
investigate the many manifestations of complementarity and antagonism of social action in the global arena" (Martinelli, 2003, 292-293).

The focus of the present study is on processes of global diffusion of WSEs over time through the observation of the diffusion over six geographical regions and over host cities in these regions. Studies on globalisation have often been criticised for adopting a limited time perspective. Moreover, Maguire (1999) argues that the study of globalisation of sport is not a recent phenomenon but a process that has already been taking place since the end of the $19^{\text {th }}$ century. Therefore, this analysis covers more than a century, beginning with the first WSE in modern sport in 1891, and covering a selection of WSEs until 2010. The purpose is to discuss two main questions: (i) Can patterns of global diffusion of WSEs be observed between 1891 and 2010?; and (ii), What are the major changes taking place in the global diffusion of WSEs over this period of time? In the discussion, contextual factors for the diffusion process will be addressed.

\section{Methods}

This study addresses the global diffusion of WSEs, from the late $19^{\text {th }}$ century to date. First, processes of globalisation are investigated by the number of editions of WSEs organised in 6 predefined geographical regions in distinct periods between 1891 and 2010. A second part of the analysis examines the diffusion of WSEs at the level of host cities within the observed regions, as an indicator of intra-continental diffusion.

In this section we present the procedure used to select the WSEs included in our study. The different steps in the selection procedure are schematically presented in Figure 1.

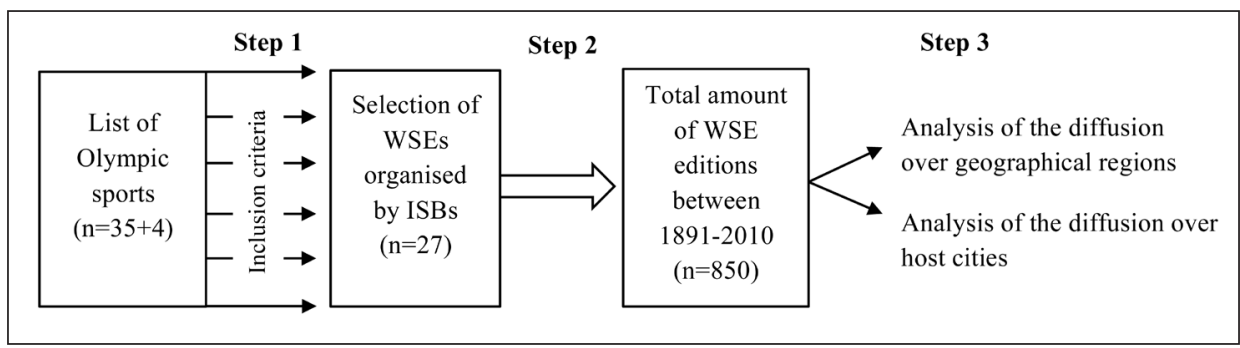

Figure 1: Three-step selection and analysis of world sports events (WSEs) organised by international sporting bodies (ISBs)

\section{Selection of world sports events}

As can be noticed from Figure 1, three steps are taken in the research process. In the first step, a selection of sports disciplines, as well as their international sporting bodies (ISBs) organising WSEs, is made. More specifically, sports disciplines with an Olympic status in $2010(\mathrm{n}=35)$ are used as a point of reference (Olympic Movement, 
2012). For each of the Olympic sports, the world's most encompassing elite sports event, that is, the World Championships, organised by an international sporting body that is recognised by the IOC, is taken into account for further analysis. Because multi sports events can also be included in the analysis, international sports events organised by the IOC (the Summer Olympic Games, the Winter Olympic Games and the Youth Olympic Games), and by the International Paralympic Committee (IPC) (the Paralympic Games) are considered for further analysis $(n=4)$.

In order to avoid any geographical bias in the study, all events representing sports disciplines that require access to particular facilities such as the sea, a lake, a river or a mountain, or that are related to specific seasonal conditions (such as winter sports), are excluded. Moreover, to be considered as a WSE for the current analysis, the sports event organised by the selected ISBs needs to meet the following inclusion criteria:

- $\quad$ The event must be organised by an ISB recognised by the IOC;

- The event must be organised with a maximum frequency of once a year;

- The event must be organised with regularity and historical continuity over the observed period;

- Every edition of the event must be linked to a geographical location and a host city ${ }^{1}$

- Hosting of the event must be held at different locations around the world;

- $\quad$ The event must be open to athletes from all over the world.

Based on these criteria, 27 WSEs can be included in the analysis. Because the first WSE ever took place in 1891 the reference period of our study covers the time interval between 1891 and 2010.

In the second step, data and locations of all of the WSE editions organised between 1891 and 2010 are gathered by using the websites of the ISBs and Wikipedia as an online data source. In this period of time, a total amount of $850 \mathrm{WSE}$ editions was organised within the 27 selected WSEs. Despite having one ISB, some WSEs have been hosted on separate locations for men and women (for example, the Hockey World Cup).

In the third step, the total amount of organised WSE editions was used for the current analysis of global diffusion over geographical regions and host cities.

Global geographical division

As the organisation of a WSE is linked to a city, a large number of host locations are expected to be found. Therefore, to structure the data the host locations are classified into macro-geographical (continental) regions, using the United Nations Standard for Country and Area Classifications (United Nations, 2012). The global regions iden-

1 For WSEs that take place over different cities during one event or tournament (e.g. the FIFA Soccer World Cup), the host city for the final was taken into account. 
tified by the United Nations (UN) are (i) Africa, (ii) Asia, (iii) Europe, (iv) Latin America and the Caribbean, (v) North America, and (vi) Oceania.

Presentation of the results

In the first part of our analysis, the diffusion of the WSEs over the six macro-geographical regions will be presented. For this analysis periods of twenty years between 1891 and 2010 will be used. The absolute and relative number of the WSE editions will be presented over the geographical regions. The time-ranges were chosen to structure the analysis without losing information. Then, those data are recaptured in three periods of 40 years to visualise the global diffusion over time in schematic maps of the world. In a second part, the focus on host cities is elaborated by the presentation of the absolute and relative number of different host cities in each of the observed geographical areas, again for every period of 20 years.

\section{Results}

Characteristics of the selected WSEs

Table 1 provides an overview of the characteristics for the selected ISBs $(n=27)$. Most of the ISBs (70.4\%) organised their first WSE in Europe. Latin America and the Caribbean and Asia are, with three start locations each (11.1\%), the second and third continents to host the first edition of an event. North America and Oceania have both been the first host location for one event, whereas none of the observed WSEs has its origin in Africa. The geographical spread of the first host locations can be considered as an indicator of the early globalisation of WSEs.

Global diffusion of WSEs over macro-geographical regions

Dividing the described era of over a century of WSEs in periods of twenty years allows the examination of the diffusion of events over time in each geographical region (Table 2). In general, the growth of the number of WSE editions observed between 1891 and 2010 is remarkable. The number of organised editions has skyrocketed, particularly in the aftermath of the Second World War. Whereas 72 WSEs were organised between 1931 and 1950, 301 WSEs took place during the last decade of the $20^{\text {th }}$ and the first decade of the $21^{\text {st }}$ century. This process of expansion is a clear indication of a globalising physical culture of elite sports spectacles. 


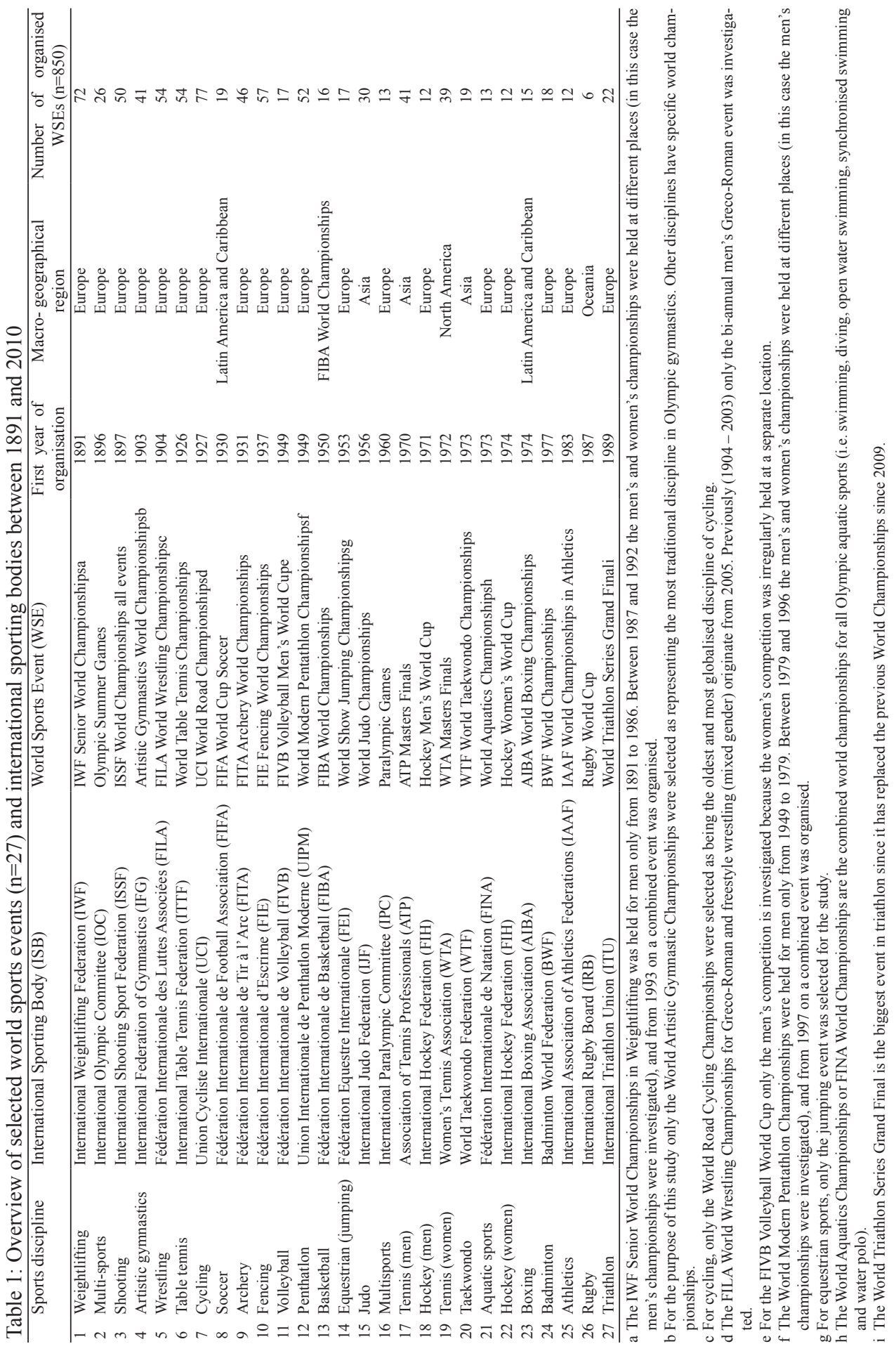


By comparing the different time-intervals, the rise of certain geographical regions and, though less pronounced, the slow-down of others is demonstrated. Apart from one or two WSE editions organised in Latin America and the Caribbean and North America in the early years, Europe (>92\%) was the main hosting region until the 1930s. Looking at the period comprising the Second World War (1931-1950), an ongoing rise in the number of WSEs is noticed in Europe (65 editions: 90.3\%). Although in this period some events were cancelled for political reasons, a slight emergence of hosting regions is observed. Also in North America (2.8\%), Latin America and the Caribbean (4.2\%) and Africa (2.8\%) WSEs were hosted during this period.

From the 1950 s on, the diffusion process is featured by an upcoming "competition' for WSEs. Due to the organisation of a substantial amount of new WSEs in other disciplines, the period between 1951 and 1970 is considered to be a period of major expansion. As a consequence, compared to the previous period, the total number of WSE editions $(\mathrm{n}=153)$ has doubled during this time-interval. An inclusion of new regions is observed, with Asia (9.2\%) and Oceania (1.3\%) hosting first major events and the Americas increasing their global share. Nevertheless, most of the WSEs were still hosted in Europe (69.9\%). This tendency is continued, however in a more pronounced globalised pattern, between 1971 and 1990.

Table 2: Absolute and relative number of WSEs according to macro-geographical regions in different observed periods $(1891-2010)(\mathrm{n}=850)$

\begin{tabular}{cccccccc}
\hline Europe & $\begin{array}{c}\text { North } \\
\text { America }\end{array}$ & $\begin{array}{c}\text { Latin } \\
\text { America } \\
\text { \& Carib- } \\
\text { bean }\end{array}$ & Africa & Asia & Oceania & $\begin{array}{c}\text { Total } \\
\text { number of } \\
\text { WSEs per } \\
\text { period }\end{array}$ \\
\hline $1891-1910$ & 37 & 1 & 1 & - & - & - & 39 \\
& $(94.1 \%)$ & $(2.6 \%)$ & $(2.6 \%)$ & & & & $(100 \%)$ \\
$1911-1930$ & 38 & 2 & 1 & - & - & - & 41 \\
& $(92.7 \%)$ & $(4.9 \%)$ & $(2.4 \%)$ & & & & $(100 \%)$ \\
$1931-1950$ & 65 & 2 & 3 & 2 & - & - & 72 \\
& $(90.3 \%)$ & $(2.8 \%)$ & $(4.2 \%)$ & $(2.8 \%)$ & & & $(100 \%)$ \\
$1951-1970$ & 107 & 11 & 18 & 1 & 14 & 2 & 153 \\
& $(69.9 \%)$ & $(7.2 \%)$ & $(11.8 \%)$ & $(0.7 \%)$ & $(9.2 \%)$ & $(1.3 \%)$ & $(100 \%)$ \\
$1971-1990$ & 137 & 56 & 21 & - & 23 & 7 & 244 \\
& $(56.1 \%)$ & $(23.0 \%)$ & $(8.6 \%)$ & & $(9.4 \%)$ & $(2.9 \%)$ & $(100 \%)$ \\
$1991-2010$ & 161 & 45 & 11 & 4 & 60 & 20 & 301 \\
& $(53.5 \%)$ & $(15.0 \%)$ & $(3.7 \%)$ & $(1.3 \%)$ & $(19.9 \%)$ & $(6.6 \%)$ & $(100 \%)$ \\
\hline
\end{tabular}

During the most recent decade (1991-2010), a notable growth in the number of WSE editions ( $\mathrm{n}=301$ ) as well as a clear global diffusion, with events being hosted in all of the six researched regions, can be detected. Although Europe remains the prominent continent in hosting WSEs in every observed period, its relative position has been declining since the early stages of globalisation of WSEs at the beginning of the $20^{\text {th }}$ 
century. In particular, since the 1970s the relative amount of WSE editions hosted in Europe (from 56.1\% to 53.5\%) and North America (from 23.0\% to 15.0\%) has declined due to a more remarkable presence of Asia (from 9.4\% to 19.9\%) and Oceania (from $2.9 \%$ to $6.6 \%$ ). From the observed WSEs, also four editions were hosted in Africa during the last observed period.

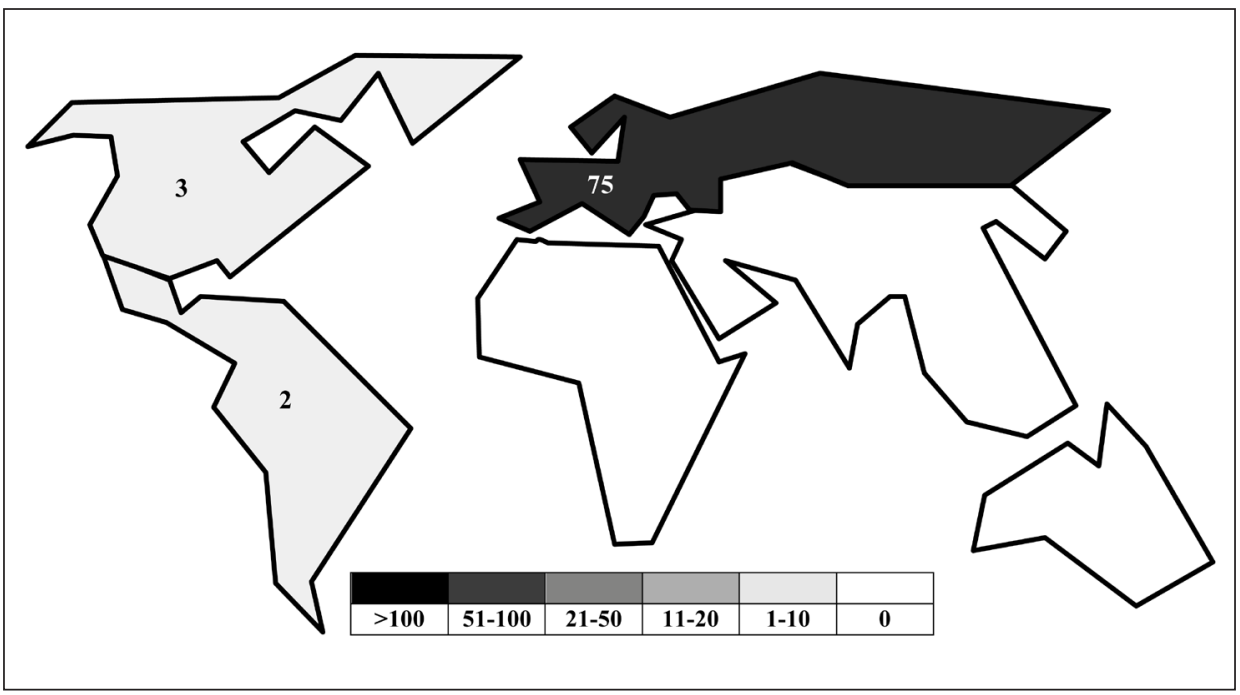

Figure 2: Absolute numbers of observed world sports events per geographical region between 1891 and $1930(\mathrm{n}=80)$

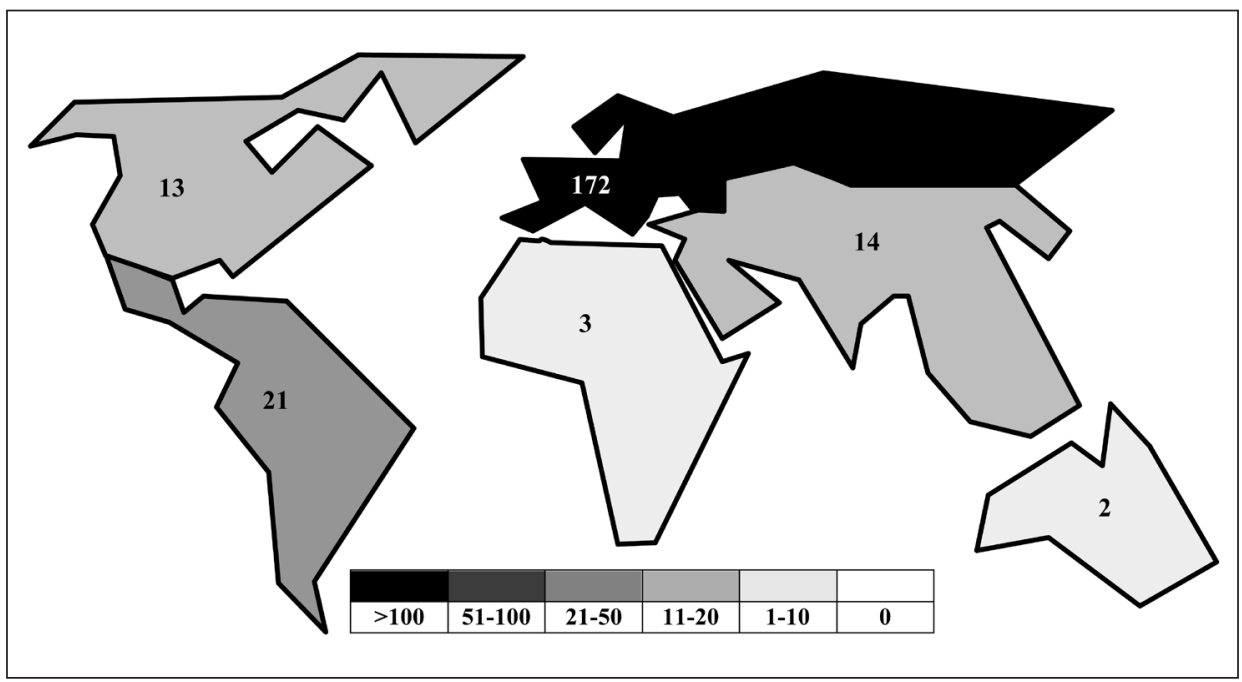

Figure 3: Absolute numbers of observed world sports events per geographical region between 1931 and $1970(n=225)$ 


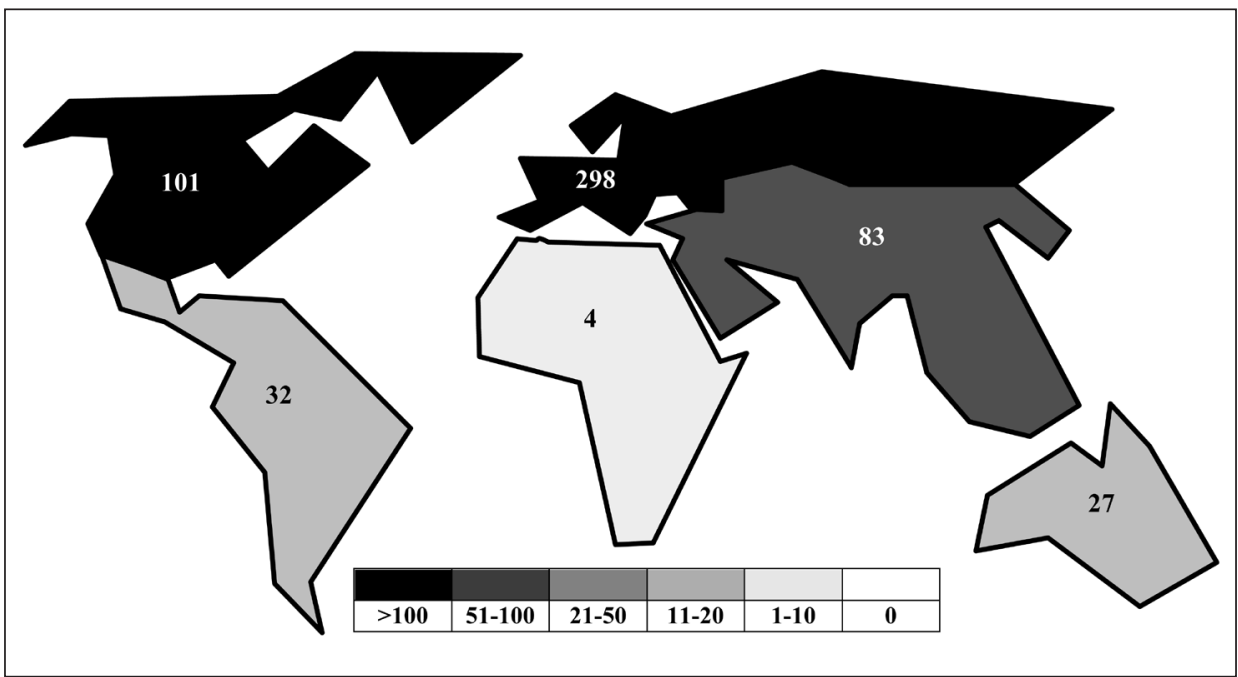

Figure 4: Absolute numbers of observed world sports events per geographical region between 1971 and $2010(\mathrm{n}=545)$

In Figures 2 to 4, the data are recaptured in three periods of 40 years. The visualisation of the results in schematic maps allows for detecting the global diffusion of host locations from a time-trend perspective. Consistent to the results described in the previous section, the evolution of the global diffusion of WSEs can be traced to three main stages: (i) an embryonic stage (1891-1930), (ii) a stage of emergence (19311970), and (iii) a stage of expansion (1971-2010).

The diffusion of WSEs over host cities

Since WSEs are mostly allocated to cities, a similar analysis is carried out relating to the diffusion of host cities over the same period of time (Table 3). The number of host cities in every period is smaller than the corresponding number of events because several cities have hosted more than one WSE. With the expansion of WSEs, the total number of host cities increased from 22 (1891-1910) to 151 (1991-2010) over the observed time span.

Before 1950, the limited number of host cities were mainly concentrated in Europe. With the growth of international competitive sport, the number of host cities multiplied and expanded across the world. Between 1951 and 1970, WSEs were organised in 91 different host cities, while in the last decade observed (2001-2010) 151 different host cities were found. Parallel to the origin and the diffusion of modern sport, the vast majority of early host cities were located in Europe, followed by North America and Latin America and the Caribbean. The growth of host cities in Asia since the 1950s is remarkable. Since 1991, multiple host cities are also located in Africa, organising major events such as the Soccer World Cup in 2010. The rising availability of different cities hosting WSEs within the broader regions can be under- 
stood both as a result and as an agent of the global diffusion of WSEs. Whereas sports organisations use the resources of cities to stage their events, cities show a vested interest in the assumed benefits of hosting WSEs.

Table 3: Absolute and relative number of different host cities within macro-geographical regions for WSEs in different observed periods (1891-2010)

\begin{tabular}{cccccccc}
\hline Europe & $\begin{array}{c}\text { North } \\
\text { America }\end{array}$ & $\begin{array}{c}\text { Latin } \\
\text { America } \\
\text { \& Carib- } \\
\text { bean }\end{array}$ & Africa & Asia & Oceania & $\begin{array}{c}\text { Total } \\
\text { number of } \\
\text { WSEs per } \\
\text { period }\end{array}$ \\
\hline $1891-1910$ & 20 & 1 & 1 & - & - & - & 22 \\
& $(90.0 \%)$ & $(4.5 \%)$ & $(4.5 \%)$ & & & & $(100 \%)$ \\
$1911-1930$ & 25 & 1 & 1 & - & - & - & 27 \\
& $(92.6 \%)$ & $(3.7 \%)$ & $(3.7 \%)$ & & & & $(100 \%)$ \\
$1931-1950$ & 33 & 2 & 1 & 1 & - & - & 37 \\
& $(89.2 \%)$ & $(5.4 \%)$ & $(2.7 \%)$ & $(2.7 \%)$ & & & $(100 \%)$ \\
$1951-1970$ & 63 & 9 & 9 & 1 & 7 & 2 & 91 \\
& $(69.2 \%)$ & $(9.9 \%)$ & $(9.9 \%)$ & $(1.1 \%)$ & $(7.7 \%)$ & $(2.2 \%)$ & $(100 \%)$ \\
$1971-1990$ & 85 & 16 & 10 & - & 15 & 5 & 131 \\
& $(64.9 \%)$ & $(12.2 \%)$ & $(7.1 \%)$ & & $(11.5 \%)$ & $(3.8 \%)$ & $(100 \%)$ \\
$1991-2010$ & 84 & 19 & 10 & 3 & 28 & 7 & 151 \\
& $(55.6 \%)$ & $(12.7 \%)$ & $(6.6 \%)$ & $(2.0 \%)$ & $(18.4 \%)$ & $(4.6 \%)$ & $(100 \%)$ \\
\hline
\end{tabular}

In general, the link between large cities and WSEs is a very important lever for the global diffusion of WSEs. Early host cities can be seen as local organisational opportunities for sports organisations in their strive towards internationalisation. More recently, the link between sporting bodies, major world cities and other significant players in the private and the public domain is fostering innovating, efficient, but complex, so-called governance arrangements needed to realise today's WSEs (Bruyninckx, 2012; Hargreaves, 2002). The concept of governance arrangements labels the growing interdependence and interaction between governmental agents, market actors and representations from civil society at different levels of policymaking (Stevis \& Bruyninckx, 2006). The increasing complexity of staging a WSE requires such flexible governance arrangements at a global level. In this perspective, the growing number of expanding mega cities might be related to the diffusion of WSEs. However, this study does not control for the pattern of diffusion of mega cities in different regions of the world over the observed periods.

\section{Discussion}

The gradual global proliferation of modern WSEs as an expression of globalising physical culture over the previous century is a remarkable feature of globalising sport. These events are now produced and consumed as mass spectacles across cultures, nations and ideologies. In particular, the profile of modernising cities in all global 
regions seem to be solid ground as production places of WSEs for global audiences. As reflected in Giddens' (1990) concept of globalisation, these sports spectacles are mostly produced locally in specific host cities and as governance arrangements in a supranational market of audiences and consumers, interrelated with events in other parts of the world.

Since the embryonic stage of modern WSEs at the end of the $19^{\text {th }}$ century, a pattern of gradual global diffusion is observed over geographical regions. Emerging from a predominantly European representation, a 50-year period of slow diffusion of WSEs emerged during the first half of the $20^{\text {th }}$ century. It is suggested that the internal development of sports organisations towards internationalisation was the primary factor in the early diffusion pattern of WSEs. However, in the second half of the century under observation, socio-economic forces external to sports organisations may have been playing an increasing role with regard to the diffusion process of WSEs. A strong expansion is observed since the 1950s: a substantial rise in the total number of events as well as diffusion across the world was observed during this period, indicating that WSEs are expanding to new regions, ideologies, economies and markets. The tendency towards globalisation was reinforced in the next period (1971-1990) by new events in almost all of the regions observed. Additionally, upcoming regions consolidate their position by frequent hosting in all of the continents during the last period observed, from 1991 to 2010. Although the number of events in Africa remains limited, its presence in the globalising arena for WSEs emerges from events recently hosted in the continent, such as the FIFA World Cup in 2010 (Cornelissen, 2004; Meulders, Vanreusel, Bruyninckx, Keim \& Travill, 2012). Although a Western dominance in hosting events is still observed, its relative share has been declining. Contrary to Dunning's (2010) statement that up-to-date sport is still not impacted noticeably by processes of 'Asianisation', we hereby argue that a shift in the production places of WSEs is being documented in the last decades. It is suggested that Asia's recent prominence in hosting WSEs coincides with the rise of East Asia and its mega cities as a power bloc since the 1950s (Brownell \& Parry, 2012), and with an increasing interest in entering the global sports market by nations located in the Middle East at the latter stage (Randeree, 2011). Data on candidate host cities, as presented by Booth (2011) and Short (2008) show that, since the new millennium, ever more different cities located in oil-based economies are pursuing the organisation of major sports events. Moreover, the fact that host cities are differentiating and growing over the years, also shows that processes of globalisation are operating within continents. Our results are consistent with Carey et al.'s (2011) statement that an increased number of 'non-traditional' cities, located in emerging economies, have entered the bidding scene of sports events.

It is well documented that WSEs have been used as a vehicle for political ideologies or as a glorification of nationalisms (Lee \& Maguire, 2009; Maguire, 2011; 
Roche, 2006; Short, 2004; 2008; Tomlinson \& Young, 2006). However, the recent expansion of WSEs appears to coincide with a growing commodification of such spectacles. It is argued that the continuing global diffusion of WSEs might rather be understood in terms of markets and consumption than in terms of nations and ideologies. According to van Bottenburg (2001) the globalisation of WSEs is breaking through original territories. Those major events are being sold in a market of bidding nations. As an example, Meulders et al. (2012) have pointed out how the 2010 FIFA World Cup in South Africa was not only a commercial product for the organising sporting body but also served as a lubricant for domestic and supranational enterprise and trade, realised by complex governance arrangements.

The global diffusion of WSEs seems to have developed from a core region (Europe) over semi-periphery regions (the Americas, Oceania) to periphery regions (Africa and Asia), which is similar to a pattern outlined by Maguire (1999) and Guttman (1994). But also Moïsi's (2009) global typology of nations can partially be traced in the diffusion pattern of WSEs, representing the West as nations of fear and Asia as nations of hope. This categorisation can be completed by emerging nations (Africa and the Middle East). Such typologies implicitly point at a power struggle and a global arena model for commodified versions of WSEs.

When appointing WSEs to particular regions, nations and cities, territoriality seems to be a main principle for the globalisation of WSEs at first glance. Cities and nation-states seek to strengthen their local territorial status, attractiveness and identity in a globalising world by hosting WSEs and by claiming the supposed and promised tangible and intangible socio-economic benefits of such events. In contrast to this view, however, we argue that the ongoing globalisation of WSEs rather refers to de-territorialisation. Because of the commodification of WSEs, such events obtain a global image as a marketing platform for globalising markets of supranational goods and services, no longer linked to a specific territoriality. As a follow-up on the concept of the borderless athlete, as presented by Chiba, Ebihara \& Morino (2001), the concept of the 'borderless WSE' can therefore be introduced. That is, borderless WSEs fit any locality in order to represent de-territorialised globalising markets.

It is tempting to describe the observed global diffusion of WSEs as a 'natural' or 'organic' process of worldwide growth and success or just as the globally increasing popularity of competitive elite sport. However, at least three comments can be made to correct this former view.

Firstly, the decision-making process that steers this global diffusion of WSEs basically lies within the powerhouses of sports organisations in interdependency with local stakeholders in host countries and host cities. As Hiller (2012) states, politicaleconomic factors play an important role in geopolitical debates to make decisions on the host location. From this perspective, bidding nations' infrastructure and resource (in)capabilities are often a decisive factor in the process of designation of the location (Cornelissen, 2004). 
Secondly, in contrast to the perception of an 'organic' worldwide cultural expansion of elite sports spectacles, the corporate control over the production and consumption of such events is increasingly strong and encompassing. Sports organisations and corporations strive to become the full legal owners and to control all the related decision-making processes. At the same time, cities and corporations seek benefits from hosting and supporting elite sports spectacles.

Thirdly, the competitive bidding process, often preceding decisions on host cities or host countries for WSEs, is commonly presented as a story of success, pride and profit for the host. At the same time, it creates an image of dependency of host cities and countries on the decision of the corporate sports world about eligibility to host a WSE. This image has recently been disturbed by several cases of withdrawal from bids to host a WSE, supported by socio-economic research that raises doubts about the supposed socio-economic profits for hosting WSEs and by protests against the bidding process itself. Bids for hosting WSEs have been questioned in the public debate, and even in national parliaments and city councils. In such situations, at least a part of the population is opposing the idea of hosting a WSE, principally for socio-economic reasons. Basic issues in this debate are doubts about the economic impact, a lack of transparency and of democratic participation in the bidding process. Whereas the bidding process for WSEs has long been dominated by a discourse of global competition, approval by sports organisations and success and local glory for the host, recently contrasting issues of reluctance, withdrawal, protest and public resistance appear in the debate on the allocation of WSEs. Such different voices add a new dimension to the debate with regard to the diffusion of WSEs: a dimension of local opposition to globalising sports culture. Again, this indicates how the global diffusion of WSEs is turning into a power struggle with local-global issues at the core of the debate. If globalisation can be understood as the intensification of interactions between local actors (Giddens, 1990), this intensification is culminating in a power struggle for control over the 'glocal' markets of WSEs, with organisations increasingly acting as transnational and multinational corporations, operating in a global market of sports spectacles in the making (Martinelli, 2003). These observations fit within Martinelli's view that "the social world in the $21^{\text {st }}$ century is both a single system and a fragmented world. Globalisation is marked by the tension between global economic and technological interdependence and social interconnectedness, on the one hand, and cultural fragmentation and political division on the other" (Martinelli, 2003, 293). The actual global production and consumption of WSEs is the result of a growing power struggle between local and global stakeholders. These stakeholders represent both the private and the public sector, with sporting bodies as hybrid semicorporate organisations in between.

Although the present paper is based on a selection of WSEs, this study did not address the rise of new sports disciplines and their organisational development 
towards WSEs over the observed period, and the decline of other sports forms. Therefore, the cultural dynamics of sports organisations and sports spectacles cannot be incorporated in the rather static selection of WSEs included in our analysis.

Another limitation of the study refers to the presentation of the results over geographical regions. Due to historical changes, no control variables such as the growth of mega cities and the emergence of new sports disciplines over the observed period are presented. Also, the focus of this study is elaborated on a fundamental macrolevel (geographical regions) and a basic micro-level (host cities). However, in order to investigate and discuss more geopolitical issues, an intermediary meso-level with a clear focus on countries or nation states can be an interesting subject to further research. It should be clarified which sub-regions, nations or cities are particularly powerful in hosting WSEs.

\section{Conclusion}

It is argued that the global diffusion of WSEs, as it is observed over more than a century, can be seen both as a consequence and as an agent of globalising physical culture. In a synthesis of globalisation research, Poli (2010) distinguished three perspectives: the 'sceptics', the 'hyperglobalists' and the 'transformationists'. The last differentiates between internationalisation and globalisation. According to Poli (2010), this perspective on globalisation is a new process comprising a spatial interdependence on a transnational scale that has not been seen before, involving both geographical spread and a high degree of functional integration and with global commodity chains as a key feature. Such commodity chains may be the key element in the proliferation and the global diffusion of WSEs. The control over these chains, or the pecking order within these chains, is the subject of a globalising power struggle. These commodity chains include local and global interests. Whereas local stakeholders seek domestic benefits and international prestige, global stakeholders seek to develop suoranational markets. While international sporting bodies, transforming into semi-corporate structures, seek to consolidate their decision-making role, the ongoing global diffusion of WSEs as spectacles of human performance and global culture is turning into an arena of global strife. As Martinelli (2003) concluded: "All of these elements can contribute to the advancement of a 'cosmopolitan project' of global governance ..., in which sites and forms of power that at present operate beyond the scope of democratic control can be made more accountable to all those who are affected by their decisions" (Martinelli, 2003, 319-320).

\section{References}

Appadurai, A. (1990). Disjuncture and difference in the global cultural economy. Theory, Culture \& Society, 7(2), 275-310. 
Bale, J. \& Maguire, J. (1994). The global sports arena: Athletic talent migration in an interdependent world. London: Frank Cass.

Booth, D. (2011). Olympic city bidding: An exegesis of power. International Review for the Sociology of Sport, 46, 367-386.

Brownell, S. \& Parry, J. (2012). Olympic values and ethics in contemporary society (Publication of the Olympic Chair Henri de Baillet Latour - Jacques Rogge). Ghent: University Press.

Bruyninckx, H. (2012). Sports governance: Between the obsession with rules and regulation and the aversion to being ruled and regulated. In B. Segaert, M. Theeboom, C. Timmermans \& B. Vanreusel (Eds.), Sports governance, development and corporate responsibility (107-121). New York: Routledge.

Carey, M., Mason, D. S. \& Misener, L. (2011). Social responsibility and the competitive bid process for major sporting events. Journal of Sport \& Social Issues, 35, 246263.

Chiba, N., Ebihara, O. \& Morino, S. (2001). Globalization, nationalization and identity: The case of borderless athletes in Japan. International Review for the Sociology of Sport, 36, 203-221.

Cornelissen, S. (2004). Sport mega-events in Africa: Processes, impacts and prospects. Tourism and Hospitality Planning and Development, 1, 39-55.

Dunning, E. (2010). Figurational/process-sociological reflections on sport and globalization: Some conceptual-theoretical observations with special reference to the 'soccer' form of football. European Journal for Sport and Society, 7, 183-194.

Giddens, A. (1990). The consequences of modernity. Cambridge: Polity Press.

Girginov, V. \& Sandanski, I. (2008). Understanding the nature of sports organisations in transforming societies. Sport Management Review, 11, 21-50.

Gold, J. R. \& Gold, M. M. (2008). Olympic cities: Regeneration, city rebranding and changing urban agendas. Geography Compass, 2, 300-318.

Gratton, C. \& Taylor, P. (2000). Economics of sport and recreation. London: E \& FN Spon.

Gugler, J. (2004). World cities beyond the West: Globalisation, development and inequality. Cambridge: Cambridge University Press.

Guttman, A. (1994). Games and empires: Modern sports and cultural imperialism. New York: Columbia University Press.

Hargreaves, J. (2002). Globalisation theory, global sport, and nations and nationalism. In J. Sugden \& A. Tomlinson (Eds.), Power games. A critical sociology of sport (25-42). London: Routledge.

Held, D., McGrew, A., Coldplatt, J. \& Perraton, J. (1999). Global transformations. Cambridge: Polity Press.

Hiller, H. H. (2012). Host cities and the Olympics: An interactionist approach. New York: Routledge.

Horne, J. (2007). The four 'knowns' of sports mega-events. Leisure Studies, 26, 81-96. 
Horne, J. \& Manzenreiter, W. (2006). An introduction to the sociology of sports megaevents. In J. Horne \& W. Manzenreiter (Eds.), Sports mega-events: Social scientific analyses of a global phenomenon (1-24). Oxford: Blackwell Publishing.

Howard, D. R. \& Crompton, J. L. (2004). Financing sport ( $2^{\text {nd }}$ ed., 161-200). Morgantown: Fitness Information Technology.

Kavetsos, G. \& Szymanski, S. (2010). National well-being and international sports events. Journal of Economic Psychology, 31, 158-171.

Késenne, S. (2005). Do we need an economic impact study or a cost-benefit analysis of a sports event? European Sport Management Quarterly, 5, 133-142.

Lee, J. W. \& Maguire, J. (2009). Global festivals through a national prism: The globalnational nexus in South Korean media coverage of the 2004 Athens Olympic Games. International Review for the Sociology of Sport, 44, 5-24.

Maguire, J. (1999). Global sport: Identities, societies and civilisations. Cambridge: Polity Press.

Maguire, J. (2011). Globalization, sport and national identities. Sport in Society, 14, 978 993.

Martinelli, A. (2003). Markets, governments, communities and global governance. International Sociology, 18, 291-323.

Meulders, B., Vanreusel, B., Bruyninckx, H., Keim, M. \& Travill, A. (2012). A governance perspective on sport mega-events. The 2010 Football World Cup in South Africa as a lubricant in domestic and international affairs? In B. Segaert, M. Theeboom, C. Timmerman \& B. Vanreusel (Eds.), Sports governance, development and corporate responsibility. Oxford: Routledge.

Miller, T., Lawrence, G., McKay, J. \& Rowe, D. (2001). Globalization and sport. London: SAGE.

Misener, L. \& Mason, D. S. (2006). Creating community networks: Can sporting events create meaningful sources of social capital. Managing Leisure, 11, 39-56.

Moïsi, D. (2009). The geopolitics of emotion: How cultures offear, humiliation, and hope are reshaping the world. New York: Doubleday.

Olympic Movement (2012). 35 sports. Retrieved from http://www.olympic.org/sports

Poli, R. (2010). Understanding globalization through football: The new international division of labour, migratory channels and transnational trade circuits. International Review for the Sociology of Sport, 35, 491-506.

Preuss, H. (2006). Impact and evaluation of major sporting events. European Sport Management Quarterly, 6, 313-316.

Preuss, H. \& Solberg, H. A. (2006). Attracting major sporting events: The role of local residents. European Sport Management Quarterly, 6, 391-411.

Randeree, K. (2011). Islam and the Olympics: Seeking a host city in the Muslim world. International Journal of Islamic and Middle Eastern Finance \& Management, 4, 211-226.

Roche, M. (2000). Mega-events and modernity. London: Routledge. 
Roche, M. (2006). Nations, mega-events and international culture. In G. Delanty \& K. Kumar (Eds.), The SAGE handbook of nations and nationalism (260-272). London: SAGE.

Schokkaert, J., Swinnen, J. \& Vandemoortele, T. (2012). Mega-events and sports institutional development: The impact of the World Cup on football academies in Africa. In W. Maennig \& A. Zimbalist (Eds.), International handbook on the economics of mega sporting events (314-335). Cheltenham and Northampton: Edward Elgar.

Short, J. R. (2004). Going for gold: Globalizing the Olympics, localizing the Games. In J. R. Short (Ed.), Global metropolitan. Globalizing cities in a capitalist world (86-108). London: Routledge.

Short, J. R. (2008). Globalisation, cities and the Summer Olympics. City, 12, 321-340.

Stevis, D. \& Bruyninckx, H. (2006). Looking through the state at environmental flows and governance. In G. Spaargaren, A. P. J. Mol \& H. Bruyninckx (Eds.), Governing environmental flows: Global challenges to social theory. Cambridge: MIT Press.

Stichweh, R. (2012). Sports as a global function system. Paper presented at the $9^{\text {th }}$ Conference of the European Association for the Sociology of Sport (eass) (Sport in globalised societies: Changes and challenges), 20-23 June. Berne, Switzerland.

Tomlinson, A. \& Young, C. (2006). National identity and global sports events: Culture, politics and spectacle in the Olympics and the Football World Cup. New York: SUNY Press.

United Nations (2012). United Nations Statistics Division: Country or area and region codes. Retrieved from http://unstats.un.org/unsd/methods/m49/m49regin.htm.

van Bottenburg, M. (2001). Global games. Urbana, IL: University of Illinois Press.

\section{Acknowledgements}

This paper was presented at the $9^{\text {th }}$ Conference from the European Association for the Sociology of Sport (eass) in 2012. We are indebted to the colleagues who commented and reviewed the paper. We are also grateful to Prof. Dr. Marijke Taks for her constructive remarks.

Julie Borgers is a PhD Student at the Policy in Sports \& Physical Activity Research Group at the University of Leuven (Belgium) and is affiliated to the Policy Research Centre on Sports (supported by the Flemish Government). Her research focuses on sports policy and sports management related to sports participation.

Katholieke Universiteit Leuven, Faculty of Kinesiology and Rehabilitation Sciences, Department of Kinesiology, Policy in Sports \& Physical Activity Research Group, Tervuursevest 101 - Bus 1500, 3001 Leuven, Belgium

E-mail: julie.borgers@faber.kuleuven.be 
Bart Vanreusel $(\mathrm{PhD})$ is Professor in the Department of Kinesiology and member of the Policy in Sports \& Physical Activity Research Group at the University of Leuven (Belgium). His research is in sociology of sport and sports policy.

Katholieke Universiteit Leuven, Faculty of Kinesiology and Rehabilitation Sciences, Department of Kinesiology, Policy in Sports \& Physical Activity Research Group, Tervuursevest 101 - Bus 1500, 3001 Leuven, Belgium

E-mail: bart.vanreusel@faber.kuleuven.be

Jeroen Scheerder $(\mathrm{PhD})$ is Associate Professor in the Department of Kinesiology and head of the Policy in Sports \& Physical Activity Research Group at the University of Leuven (Belgium). He lectures in the fields of public sport policy and sport management. His research focuses on policy-related and socio-economic aspects of sport and physical activity.

Katholieke Universiteit Leuven, Faculty of Kinesiology and Rehabilitation Sciences, Department of Kinesiology, Policy in Sports \& Physical Activity Research Group, Tervuursevest 101 - Bus 1500, 3001 Leuven, Belgium

E-mail: jeroen.scheerder@faber.kuleuven.be 